\title{
Study on Ideological \& Political Education in Colleges under background of New Media Era
}

\author{
Yaling Dai ${ }^{1, a}$ \\ Teacher's College, Beihua University, 132013, Jilin City, China
}

Keywords: Colleges, ideological and political education, far-reaching strategic, new media era

\begin{abstract}
In order to ensure effective implementation of the sharing community model in ideological and political education under the background of new media era, it is essential to build sound evaluation mechanism in sharing community, which is the need not only to correctly evaluate the effects of sharing community in ideological and political education and to realize the control of educators on the process of ideological and political education, but also the guarantee to achieve the goals of ideological and political education under the new media era.
\end{abstract}

\section{Introduction}

The so-called "Time" is a concept of time and space with people closely linked, is the human consciousness can affect all the objective environment. As used herein, the alleged "new media era" is a relative concept, compared with the human history appear on the media age, its distinctive era is mainly reflected in three aspects: First, the height of the media convergence. The process of formation of the new media are different forms of old and new media converge with each other, blend, to achieve a variety of media increasingly more integrated process. Compared with the old media and new media integration ability is reaching alarming proportions: it includes integration of multiple media forms in the physical and technical level, including integration of different forms of content and distribution channels, and even the media culture, market, value integration and other aspects of the show that it is a profound transformation of the media and revolutionary change. Second is to have great energy. With the advancement of technology and economic growth, the spread of new media with unprecedented capability and coverage on a human history, Earth people into the new media environment among objective and consciously or unconsciously, have become the audience, and its long-lasting and profound influence exerted. Once again, the neutral characteristic instrumental. As a product of scientific and technological revolution, the identity of new media technology tools that it and any technology inventions, characterized by having a neutral tool, no one has to be used and will not have different users have different effects. However, the new media, once used by political act, it is not just technology tools, can also become a political tool, the pursuit of political power and political interests of the tool, it has a "non-neutral" role of this "non-neutral" role because it is being used to produce the salient features of a new media era.

At present, China is in the social transition period, differentiation diverse social strata and interest to bring a wide range of value orientation, because of people's ideas, such as unfair distribution of influence, wealth gap phenomenon tends to utilitarian and reality. Meanwhile, with the increasing popularity of new media and applications coming era, the Internet, mobile phones and other new media, all kinds of Western ideology, social thoughts through various channels into China, the mainstream socialist ideology huge hit. As one of the college students, "Being Digital," the experience of those who first obtained with the simultaneous development of the world and in order to fully demonstrate personal space, their ideas, knowledge acquisition, value orientation, interpersonal and behaviour, but also has been deeply to mark branded on the new media era. Research and strengthening the new media era of ideological and political education to improve the ideological and political quality of college students, for the full implementation strategy and this strategy, speed up the completion of a comprehensive well-off society and promoting socialist modernization grand goal of socialism with Chinese characteristics to ensure prosperity developed, successors, have a very significant and far-reaching strategic significance. The new media digestion

\footnotetext{
${ }^{\mathrm{a}}$ Corresponding author: yalingdai001@126.com
} 
boundaries between traditional media, digestion of the boundary information between the sender and the recipient, and the mass media become pro and a small minority, libertarian audience reflected.

\section{The essential difference between old and new media}

The definition given herein, with respect to the difference between old and new media, is not that time has appeared, not just stay in the technical aspects, but not a simple functional alternative, but an idea of innovation. As the French philosopher Jean Baudrillard expressed: "The railroad brought' information ', it is not coal or passenger transport, but a world view, a new combination of state." Distinction between the nature of old and new media: to see whether the media can bring about change people's way of living, whether human nature will help the realization of freedom.

Compared with the old media, new media, "new" in the following aspects: a new concept: Marx pointed out, the reason why people lose freedom, not because he has no sense of freedom, but "forced by force of the historical process." Essence of human freedom determines man's social practice, has a certain purpose, direction and initiative, practice that has the value and significance of the problem. Meaning and value realization is achieved in the interaction, therefore, to achieve free will through effective communication, for the essence of human freedom is of great significance. Traditional media, many media mode, dominate the right to speak, man's free will in the medium cannot be achieved even before being buried, human free will highlight the need for an alternative means of communication, to break the existing spread of hegemony this need to spread the revolution in the way, but also need to spread support innovation. The new media digestion boundaries between traditional media, digestion of the boundary information between the sender and the recipient, and the mass media become pro and a small minority, libertarian audience reflected.

\section{Characteristics of the new media}

\subsection{Subject equality and freedom}

Traditional media (newspapers, radio, television, etc.) released information is generally provided by a professional, in addition to being its contents affect the value of professionals represented groups, should also be subject to audit departments, and in the audience of communicators inter showed some unequal nature. Extensive application of new media, except for the outer part of the dissemination of information is provided by professionals, such as more information (SMS, microblogging, forums, etc.) are provided by the public, anyone can through the network, microblogging, QQ, Fetion WBL and other new media tools are free to express their personal opinions, to express their ideas. Different individuals publish information, opinions, and to express their views are equal is a personality.

Everyone is both a publisher of information, is the recipient of information. So, it also means that everyone is both a trainer who is also the educated. Virtual information dissemination of new media, but also refers to the spread of virtual sexual relationship, in this virtual relationships, we can easily hide their identity, only use professional tools or professional and technical means to effectively get rid of this kind of hidden. Occult also increases the sense of security information between the two sides, the traditional communication process to reduce possible interference objective factors for the exchange of both the freedom to distribute or receive information to provide the conditions.

\subsection{Content with the mass of immediacy}

Send due to restrictions from the printed information, transportation, distribution and other objective factors, real and mass media of a new communication process typical characteristics. Such as SMS, microblogging, shoot-off, etc., which can transmit information almost simultaneously with the event, and spread in a non-linear state. From the perspective of the social field of view, relying on information dissemination of new media are government-oriented public information released to 
the public, educational information school students and parents or teachers to publish, but also commercial business information to consumers or other businesses released there are organizations, groups and individuals about the work of independent publishing, entertainment and leisure life of the individual information.

\subsection{Forms of digital and interactive technology}

The most important feature of the new media is the progress of science and technology brought about by digital transmission. Digital is the many complex information into measurable digital data, then these figures, data to establish the appropriate digital model, put them into a series of binary code (which consists of two basic character $1 \mathrm{~s}$ and 0s, binary code binary arithmetic rule is every a), introduced inside the computer, unified process, through permutations and combinations to represent and disseminate information, which is the basic process of digitization. People can adjust this arrangement to create and modify the information (text, images, video, sound, etc.), and even creates realistic virtual information, such as digital animation, computer games and the like.

Interactivity is the new media is different from the conventional media, the most prominent feature, contains two meanings: First, the exchange of information between the sender and receiver of information is two-way; the second is to participate in the two sides have the right to speak in the process of information exchange and Control. Traditional media (press, radio, film, television, etc.) has a one-way exchange of information, feedback slower, interactivity is relatively poor. Digital technology makes information collection and production becomes easy, as long as the individual using text input system (computers, mobile phones, etc.), digital cameras, you can easily edit or send text and pictures. By Digitization important characteristics of the new media, everyone can receive information and complete communication and information at the same time. In the new media age, the information exchanges between the dissemination of information is used in two-way interactive way, which facilitates timely understanding and communication.

\subsection{Context fragmentation and virtualization}

Fragmentation is a description of an image of the current Chinese social communication context argument. Intended for the complete thing broken into many zero blocks, it is that people learn to read the media through the network very much information, but there is no deep understanding and memory, so that they know something. New media surge passage, freedom of expression and the accumulation of vast amounts of information, so that in the past had to rely on one (class) era strong media coverage or cultural past.

\subsection{Personalized service with the reading public share}

It has its own personality and desire for freedom in the face of a phenomenon or a news, no one is willing to fully accept the ideas of others, everyone has to express their wishes; or no one wants to wear the same clothes and others stay Like hair, because that "I" concept will become blurred. Web2.0-based information technology platform, so that each participant has a terminal information (such as IP address, phone number, etc.), communicators can easily categorize information, and sent to each address. Furthermore, the audience can also be customized and retrieving information via the new media, such as the various search engines. Thus, each new media users can publish and receive fully personalized information, mass media into "small diffusion."

\section{Characteristics and requirements of the new media era of ideological and political education}

Ideological and political education of the concept has evolved from political work, ideological work, ideological and political work, political and ideological work and other terms, the concept of ideological and political education of understanding, similar to those in the comparative study of the concept of gradually clarity. I quite agree, Professor Zhang Yaocan definition of ideological and political education, the ideological and political education refers to a certain class, political parties and social groups to follow the law of development of people's ideological and moral formation, 
with certain ideas, political views, ethics, applied to its members purposeful, planned, organized influence, so that they form social practices comply with certain moral society, a certain class of required. Traditional media (press, radio, film, television, etc.) has a one-way exchange of information, feedback slower, interactivity is relatively poor. Digital technology makes information collection and production becomes easy, as long as the individual using text input system (computers, mobile phones, etc.), digital cameras, you can easily edit or send text and pictures.

\subsection{Complicated ideological and political education environment}

New media to break the constraints of time, the main characteristics of digestion boundary line closer distance, while a certain extent, may also alienated from the reality, human skills decline, prone to lead to a crisis of confidence and psychological personality disorder and other psychological problems, college students "network obsessive disorder," "network autism", "mobile phone syndrome" are common occurrences. At the same time, new media not only provides entertainment, seek spiritual comfort, vent complaints and other escapist activities homeland, but also provides a variety of soil caused by personality disorders and cybercrime, constraints forced indoctrination and public opinion ideological and political education force, with the advent of the new media age and lost their original advantage, ideological and political education to guide and regulate the difficulty of growing, increasingly complex environment.

\subsection{Ideological and Political Education Subject characteristics become evident}

New media era of ideological and political education main features include two aspects: First, educators' subjectivity. New media makes ideological and political education to become a flexible way, educators in order to receive the best educational results, it must give full play to the initiative and enthusiasm, efforts to explore effective ways in the new media environment of ideological and political education. Second, the mass of information given to college students according to their needs information opportunities, which meet the broad participation and acceptance of university students' enthusiasm education, respect and play the subjectivity of the educated, can make education more relevant. In the traditional ideological and political education, the relationship between education and by the presence of educational reality, so that educators are often seen as ideological authority ideological indoctrination. In the new media age, the social reality of gender, identity and privileges of other factors are weakening, everyone can express their views and seek equal exchange of objects. This subversive sense of authority and social hierarchy reality pursued, greatly enhance the respect for individual dignity, recognition of individual rights and cultural awareness.

\subsection{Ideological and political education of three-dimensional sources of information}

Traditional ideological and political education is an important source of information from a large number of theories, principles and policies, political strong, coupled with the limited amount of information and content lag, lack of modern, attractive. In the previous discussion of new media when the concept has to be demonstrated capacity and nature of new media, the intensity of the impact of new media rendering three-dimensional, has been far greater than in the past have used any means of communication. Educators have long educated or a networked computer, a IPAD, a mobile phone, you can quickly and easily obtain and disseminate large amounts of real-time information to understand foreign political, cultural, economic, ideological, social life, but also can exchange of ideas and information anytime, anywhere, when national boundaries, time and space, race, gender, age has been crossed, information sources and communication channels become threedimensional.

\subsection{Diverse ideological and political education means}

Time and space constraints of ideological and political education has occurred because of the new media and migration, the traditional way of education is provided to students must place 
education within a specified period of time, and the new media age, education and being taught in any the terminal has spread at any time and place to obtain the required knowledge. While education may take the form of education also tend to diversity, can take advantage of the multiple functions of the new media, organized students to watch high-quality video open class, cinema, discussion, online job, talking heart to heart, and so on. Means of education also tend to modernization. Traditional ideological and political education, mostly using this ancient way of lectures, educators need to spend a lot of time and effort to find information on paper and write lecture notes, covered with eyes and thick sheaf of papers and seriousness indoctrination bloodshot, it seemed effect minimal. As McLuhan said "the medium is an extension of human organs", the use of new media, not only reduces the burden on teacher preparation, but also ideological and political education to improve the speed and efficiency of information dissemination and diverse forms of information to stimulate multiple senses, students easy accept. In particular, the use of virtual information and communication technology for the live holographic video animation and other multimedia simulation screen, you can make teaching becomes interesting, the effect is enhanced.

\subsection{Ideological and political effects of economic education}

Ideological and political education website nonlinear propagation of new media technology under, or symposiums on the major portals, or surging each topic, there is a common feature is the ability to realize the sharing of information, both to avoid the human, material waste, and reasonable allocation of educational and teaching resources. Meanwhile, school, family and social environment of these three ideological and political education can form an educational force, schools can keep in touch with parents at any time, parents can always check online child thinking in the school situation, the community media or related sectors it can also supervise the success of ideological and political education. In short, the ideological and political education school Gao Only organic fit new media to observe the broader vision of the world, efforts to achieve ideological and political education philosophy, content, method, system, and so comprehensive and innovative in order to obtain the value of the new media environment of the foundation, through new media technologies to gather social resources, strengthen education and guidance, and strive to improve the attractiveness of the ideological and political education, appeal, complete guide people, shaping people's mission to enhance ideological and political work more targeted and effective.

\section{Conclusion}

In contemporary China, to create a new media network with its virtual community, openness, efficiency, broad, clustering, control, autonomy and democracy and other characteristics, formed a relatively complete social structure and function, it and China has been nomadic society, agricultural society, industrial society and the information society and other social realities exist simultaneously, interacting with each other, forming a vibrant contemporary China, complex, risky new space, not only the process of human interaction, ways of thinking and lifestyle fashion has undergone profound changes, but also directly led to the emergence of a whole social structure to build. "With the discovery of the natural sciences every epoch of materialism is also bound to change their form." The new state compared with the conventional form of ideological and political education, new media era of ideological and political education is the new media need to be born of ideological and political education.

\section{References}

1. Rong Yaojun: "Modernity and Cultural Criticism in the media as a body type from Benjamin, McLuhan to Baudrillard" Xiamen University (Philosophy and Social Science) 3 (2008).

2. Zheng Yuanjing: Effectiveness of ideological and political education in the new media environment of Ideological and Political Education], 11 (2011). 
3. Zhang The power in the new media environment generation modern ideological and political education school party building and ideological and political education, 11 (2011).

4. Mu Xiang Wang: public opinion function of Network Media Environment Information Science, 7 (2007).

5. Jin Tianwei: New Media Influence and Strategy of College Students' Modern Property (in Xunkan), 4 (2011).

6. Qiuren $\mathrm{Fu}$ : ideological and political education discourse basic structure and function of ideological and political education research, 1 (2015).

7. Miao Yanmei: About communities and types Review of Hubei Radio and TV University, 10 (2005).

8. CPC Central Committee and State Council on further strengthening and improving ideological and political education. Beijing Daily, 2004-10-15.

9. The Central Propaganda Department, Ministry of Education Opinions on Further Strengthening and Improving Ideological and Political Theory Course in colleges and universities. Publication People's Republic of China Ministry of Education, 5 (2004). 